\title{
Analysis of caesarean section in a tertiary care hospital, Assam, India
}

\author{
Alaka Banerjee ${ }^{1}$, Banasree Bhadra ${ }^{2 *}$, Kiriti R. Dey ${ }^{1}$ \\ ${ }^{1}$ Department of Obstetrics and Gynaecology, Silchar Medical College, Silchar (Cachar), India \\ ${ }^{2}$ Department of Obstetrics and Gynaecology, College of Medicine and JNM Hospital Kalyani (Nadia), West Bengal, \\ India
}

Received: 26 January 2018

Accepted: 28 February 2018

\author{
*Correspondence: \\ Dr. Banasree Bhadra, \\ E-mail: banasree22@yahoo.com
}

Copyright: (c) the author(s), publisher and licensee Medip Academy. This is an open-access article distributed under the terms of the Creative Commons Attribution Non-Commercial License, which permits unrestricted non-commercial use, distribution, and reproduction in any medium, provided the original work is properly cited.

\begin{abstract}
Background: One of the commonest surgery performed worldwide is caesarean Section (CS). The World Health Organization (WHO) has identified an ideal caesarean section (CS) rate for a nation of around 10-15\%. In recent times the proportion of delivery conducted by caesarean section has increased.

Methods: This is a retrospective study of all the caesarean deliveries performed between $1^{\text {st }}$ January 2010 to $31^{\text {st }}$ December 2018 in the Department of Obstetrics and Gynaecology in Silchar Medical College. The caesarean rate was calculated as: (total number of caesarean deliveries/ total number of deliveries) $\times 100$. The indications for CS included foetal distress, malpresentation, previous caesarean section, multiple gestation, failed induction, failed progression, cephalopelvic disproportion, maternal indications, obstetric indication and foetal indications.

Results: During the study period a total of 75685 patients delivered. 25805 patients had undergone CS with the CS rate being around $34.1 \%$. Majority of the CS $(75.6 \%)$ were performed as emergency procedure. Maximum number of patients were between 21-30 years (73.24\%) and 54.47\% were primipara. Majority of the patients $(68.37 \%)$ belonged to the rural areas. Foetal distress $(32.8 \%)$ was the commonest indication followed by post caesarean pregnancy $(26.76 \%)$.

Conclusions: The rate of caesarean section is increasing with time. As primary caesarean section usually determines the lady's future obstetric course, it is of prime importance to give effort for safe reduction of caesarean. Individualization of the indication and careful evaluation, following standardized guidelines and practice of evidencedbased obstetrics followed by audits in the institution, can help us limit the caesarean rates.
\end{abstract}

Keywords: Caesarean section, Indications, Rate

\section{INTRODUCTION}

One of the commonest surgery performed worldwide is caesarean section (CS). The surgery should only be performed when there is a valid reason to do so. The World Health Organization (WHO) has identified an ideal caesarean section (CS) rate for a nation of around 10$15 \% .{ }^{1}$ In recent times the proportion of delivery conducted by caesarean section has increased and has reached the epidemic proportion in some parts of the world. It has been suggested that factors, such as social, cultural, unequal accessibility to health services and clinical practice patterns might have been major contributors to the wide variation in caesarean section rates across different countries. ${ }^{2,3}$ The increasing trend of CS rates may indicate a trend towards a costlier medical delivery systems and lowered threshold of abnormality detection among the health care providers. ${ }^{4}$ Studies have shown that there is no evidence of benefit for the health of mothers and babies in populations with values of CS rate above $15 \% .^{5,6}$ In fact, caesarean deliveries are associated with increased risk of maternal and perinatal morbidity as compared to vaginal 
deliveries even in low risk cases. ${ }^{7}$ This study is aimed to find the rate of caesarean deliveries and various indications of the procedure. This analysis may help to find out various ways to reduce the incidence of caesarean rate in the institute in future.

\section{METHODS}

This is a retrospective study of all the caesarean deliveries that occurred in the period between $1^{\text {st }}$ January 2010 to $31^{\text {st }}$ December 2018 in the Department of Obstetrics and Gynaecology in Silchar Medical College. This is a tertiary care hospital receiving referred patients from nearby rural sub divisional hospitals, peripheral health centres and also nursing homes.

Data were analysed from the hospital records. Maternal data collected included the age, parity, type of CS and indication of CS. The caesarean rate was calculated as:

(Total number of caesarean deliveries / Total number of deliveries) $\times 100$.

The indications for caesarean section included foetal distress, malpresentation, previous caesarean section, multiple gestation, failed induction, failed progression (including failed forceps or vacuum extraction), cephalopelvic disproportion, maternal indications, obstetric indication and foetal indications.

In the present study, foetal distress includes foetal distress during labour, and abnormal umbilical artery Doppler study. Maternal indications include the maternal conditions predating the pregnancy that could complicate delivery like complete perineal tear, medical causes, post myomectomy etc. Obstetric indications were placenta previa, abruptio placentae, placenta accreta, cord prolapse etc. Foetal indications included intrauterine growth restriction, prematurity, and congenital malformations in which vaginal delivery was not possible.

\section{RESULTS}

During the study period a total of 75685 patients delivered and 25805 patients had undergone caesarean section.

Table 1: Year wise deliveries, caesarean section and caesarean section rates.

\begin{tabular}{|llll|}
\hline Year & $\begin{array}{l}\text { Total } \\
\text { deliveries }\end{array}$ & $\begin{array}{l}\text { Caesarean } \\
\text { section }\end{array}$ & Rate of CS \\
\hline 2010 & 7843 & 2154 & $27.5 \%$ \\
\hline 2011 & 8159 & 2378 & $29.1 \%$ \\
\hline 2012 & 9038 & 2848 & $31.5 \%$ \\
\hline 2013 & 9677 & 3174 & $32.8 \%$ \\
\hline 2014 & 10001 & 3605 & $36.04 \%$ \\
\hline 2015 & 10084 & 3538 & $35.08 \%$ \\
\hline 2016 & 10071 & 3819 & $37.9 \%$ \\
\hline 2017 & 10812 & 4289 & $39.6 \%$ \\
\hline
\end{tabular}

Year wise deliveries, caesarean section and caesarean section rates in the hospital from 2010 to 2017 is shown in Table 1. Caesarean rates were lowest in 2010 (27.5\%) and highest in 2017 (39.6\%).

Table 2: Caesarean section rates.

\begin{tabular}{|lll|}
\hline Mode of delivery & No. of cases & Percentage \\
\hline Vaginal delivery & 49880 & 65.9 \\
\hline Caesarean delivery & 25805 & 34.1 \\
\hline Total & 75685 & \\
\hline Type of caesarean & & \\
\hline Emergency & 19508 & $75.6 \%$ \\
\hline Elective & 6297 & $24.4 \%$ \\
\hline
\end{tabular}

Table 2 shows that the caesarean section rate at the institution comes to be around $34.1 \%$ whereas vaginal delivery rate was $65.9 \%$. Majority of the CS $(75.6 \%)$ were done as emergency procedure as patients mostly came to this hospital when there was emergency or were referred. Only $24.4 \%$ cases had elective CS.

Table 3: Demographic analysis of patients who underwent caesarean.

\begin{tabular}{|llll|}
\hline Parameters & No. of & $\begin{array}{l}\text { Percentage } \\
\text { cases }\end{array}$ & 20 years and \\
below & 3826 & 14.8 \\
\hline \multirow{2}{*}{ Age } & 21-30 years & 18902 & 73.24 \\
\cline { 2 - 4 } & 31-40 years & 2814 & 10.9 \\
\hline \multirow{2}{*}{ Parity } & $>40$ years & 263 & 1.01 \\
\hline \multirow{2}{*}{ Residence } & Primi & 14057 & 54.47 \\
\hline & Multi & 11748 & 45.52 \\
\hline & Rural & 17643 & 68.37 \\
\hline
\end{tabular}

Demographic analysis shows maximum number of patients to be between 21-30 years (73.24\%). Those of 20 years and below were $14.8 \% .14057$ patients $(54.47 \%)$ were primipara and $45.52 \%$ cases were multipara (Table $3)$. Majority of the patients $(68.37 \%)$ belonged to the rural areas and $31.63 \%$ cases were from urban areas.

Table 4: Indication of caesarean deliveries.

\begin{tabular}{|lll|}
\hline Indication & No. of cases & Percentage \\
\hline Foetal distress & 8462 & $32.8 \%$ \\
\hline Malpresentation & 1893 & $7.33 \%$ \\
\hline $\begin{array}{l}\text { Post caesarean } \\
\text { pregnancy }\end{array}$ & 6905 & $26.76 \%$ \\
\hline Failed induction & 948 & $3.67 \%$ \\
\hline Failed progression & 2706 & $10.5 \%$ \\
\hline $\begin{array}{l}\text { cephalopelvic } \\
\text { disproportion }\end{array}$ & 476 & $1.84 \%$ \\
\hline Multiple pregnancy & 695 & $2.7 \%$ \\
\hline Maternal indication & 492 & $1.9 \%$ \\
\hline Obstetric indication & 2137 & $8.2 \%$ \\
\hline Foetal indication & 1091 & $4.2 \%$ \\
\hline
\end{tabular}


Among the indications, it was observed that foetal distress $(32.8 \%)$ was the commonest cause followed by post caesarean pregnancy $(26.76 \%)$ as shown in table $4.10 .5 \%$ cases were due to failed progression and obstetric indication constituted $8.2 \%$.

\section{DISCUSSION}

Although the CS rate is said to vary from region to region and from one country to another, worldwide there has been an increasing trend of caesarean section deliveries. Manjulatha B et al found the CS rates to increase from $16.6 \%$ in 2002 to $22.4 \%$ in $2012 .{ }^{8}$ Present study also showed an increase in CS rates from $27.5 \%$ in 2010 to $39.6 \%$ in 2017 . In the present study we found the CS rate of the institution to be $34.1 \%$ which is similar to the findings of Bhasin SK et al. ${ }^{9}$ Santhanalakshmi C et al found CS rate to be comparatively lower $(12.5 \%)$ whereas $\mathrm{G}$ Singh et al and Haidar G et al (Pakistan) reported CS rate as high as $51.1 \%$ and $67.7 \%$ respectively. ${ }^{10-12}$

The reasons for the increase in the caesarean rates are multifaceted. Detection of foetal distress especially with the use of continuous electronic foetal monitoring may be an important reason. Liberal use of caesarean in high risk cases like breech presentation, previous caesarean delivery, growth retarded foetus etc along with avoidance of difficult manipulative or instrumental vaginal deliveries may be some other reasons. Our institution which is a tertiary centre gets a large number of complicated pregnancies as well as referred patients in critical stage which makes it difficult to keep the CS rates low.

In the present study majority of the CS (75.6\%) were performed as emergency cases which is comparable with findings of Gupta $\mathrm{M}$ et al who found emergency cases to be $62.08 \% .^{13}$

Demographic data analysis of the present study showed that $73.24 \%$ cases belonged to $21-30$ years which is similar to the findings of Jawa A. ${ }^{14}$ Majority of our cases (68.37\%) belonged to rural areas whereas Gupta $\mathrm{M}$ et al found most of the cases belonging to urban areas. The location of the institution and the type of health care facility available in nearby areas play a vital role in this matter.

In the present study, foetal distress was the commonest indication (32.8\%) of CS. Studies by Barber EL et al and Liu $\mathrm{S}$ et al also showed similar results. ${ }^{15,16}$ This is in contrast to the findings of Santhanalakshmi $\mathrm{C}$ et al and Gupta $\mathrm{M}$ et al where previous caesarean was the leading indication of CS. ${ }^{10,13}$ The most accurate method for establishment of foetal distress is to perform foetal scalp blood $\mathrm{pH}$ estimation but in our setup this was not performed. The post caesarean cases accounted for the second commonest indication in out hospital (26.76\%). The incidence of CS in previous CS case can be minimized by routine practice of a trial of labour of Vaginal Birth After Caesarean (VBAC). VBAC is less in our hospital due to details regarding previous CS mostly being not available, doubtful scar strength, greater number of complicated referral cases to deal with and shortage of trained personnel for continuous monitoring of such cases. Few studies found that VBAC with a well-defined protocol was found to safe for the mother and infant as a planned caesarean delivery and can be encouraged. ${ }^{18,19}$ However, McMahon et al noted that higher rates of maternal and foetal morbidity exist with VBAC as compared to elective caesarean. ${ }^{20}$

Failed progression constituted $10.5 \%$ of the indications in our study which is similar to the findings of the study done by Gupta M. Judicious use of oxytocics and maintenance of a partogram in cases of failure to progress will help reduce the rate of $\mathrm{CS}$ in such cases. Obstetric indications constituted $8.2 \%$ of the indications. Being a referral centre our hospital has to deal with more number of such cases.

\section{CONCLUSION}

With passing time, the rate of caesarean section is increasing. As primary caesarean section usually determines the future obstetric course of a lady, it is of prime importance to give effort for safe reduction of caesarean. Individualization of the indication and careful evaluation, following standardized guidelines and practice of evidenced-based obstetrics followed by audits in the institution, can help us limit the caesarean rates.

\section{ACKNOWLEDGMENTS}

Authors are thankful to the hospital authorities, the record section and the head of the Department of Obstetrics and Gynaecology for allowing the authors to collect the hospital data for preparing this article.

\section{Funding: No funding sources Conflict of interest: None declared \\ Ethical approval: The study was approved by the Institutional Ethics Committee}

\section{REFERENCES}

1. Betran AP, Torloni MR, Zhang JJ, Gülmezoglu AM, WHO Working Group on Caesarean Section. WHO Statement on Caesarean Section Rates. BJOG. 2016;123(5):667670.

2. Zhang J, Troendle J, Reddy UM, Laughon SK, Branch $\mathrm{DW}$, Burkman $\mathrm{R}$, et al. Contemporary cesarean delivery practice in the United States. Am J Obstet Gynecol. 2010;203:326.e1-.e10.

3. Fioretti B, Reiter M, Betran A, Torloni M. Googling caesarean section: a survey on the quality of the information available on the Internet. BJOG. 2015;122:731-9.

4. Mukherjee SN. Rising cesarean section rate. J Obstet Gynecol India. 2006;56(4):298-300.

5. Betrain AP, Merialdi M, Lauer JA, Bing-Shun W, Thomas J, Look VP, et al. Rates of caesarean section: 
analysis of global, regional and national estimates. Paediatr Perinat Epidemiol. 2007;21(2):98113.

6. Althabe F, Sosa C, Belizán JM, Gibbons L, Jacquerioz $\mathrm{F}$, Bergel E. Cesarean section rates and maternal and neonatal mortality in low-, medium-, and highincome countries: an ecological study. Birth. 2006;33 (4):2707.

7. Belizán JM, Cafferata ML, Althabe F, Buekens P. Risk of patient choice caesarean. Birth. 2006;33:1679

8. Manjulatha B, Sravanthi TP. Caesarean section rates in a Teaching Hospital: a ten-year review. IOSR J Dent Med Sci. 2015;14(8):1-5.

9. Bhasin SK, Rajoura OP, Sharma AK, Metha M, Gupta N, Kumar S, et al. A high prevalence of caesarean section rate in East Delhi. Indian $\mathrm{J}$ Comm Med. 2007;32(3):222-4.

10. Santhanalakshmi C, Gnanasekaran V, Chakravarthy AR. A Retrospective Analysis of Cesarean Section in a Tertiary Care Hospital. Int J Sci Res. 2013;4(9):2097-9.

11. Singh G, Gupta ED. Rising incidence of caesarean section in rural area in Haryana, India: a retrospective analysis. Internet J Gynecol Obstet. 2013;17(2):1-5.

12. Haider G, Zehra N, Munir AA, Haider A. Frequency and indication of caesarean section in a tertiary care hospital. Pak J Med Sci. 2009;25(5):791-6.

13. Gupta M, Garg V. The rate and indications of caesarean section in a teaching hospital at Jaipur, India. Int J Reprod Contracept Obstet Gynecol 2017;6:1786-92.

14. Jawa A, Garg S, Tater A, Sharma U. Indications and rates of lower segment caesarean section at tertiary care hospital-an analytical study. Int J Reprod Contracept Obstet Gynecol. 2016;5:3466-9.

15. Barber EL, Lundsberg LS, Belanger K, Pettker CM, Funai EF, Illuzzi JL. Indications contributing to the increasing cesarean delivery rate. Obstet Gynecol. 2011;118(1):29-38.

16. Liu S, Rusen ID, Joseph KS, Liston R, Kramer MS, Wen SW, et al. Maternal Health Study Group of the Canadian Perinatal Surveillance System. Recent trends in caesarean delivery rates and indications for caesarean delivery in Canada. J Obstet Gynaecol Can. 2004;26(8):735-42.

17. Nelson JP. Indications and appropriateness of caesarean sections performed in a tertiary referral centre in Uganda: a retrospective descriptive study. The Pan African Med J. 2017;26:64.

18. Gonen R, Tamir A, Degani S. Variables associated with successful vaginal birth after one caesarean section: a proposed vaginal birth after caesarean section score. Am J Perinatol. 2004;21:447-53.

19. Kugler E, Shoham-Vardi I. The safety of a trial of Labour after caesarean section in a grand multiparous population. Arch Gynaecol Obstet. 2008;277:339-49.

20. McMahon MJ, Luther ER, Bowes WA Jr, Olshan AF. Comparison of a trial of labor with an elective second cesarean section. N Engl J Med. 1996;335(10):68995.

Cite this article as: Banerjee A, Bhadra B, Dey KR. Analysis of caesarean section in a tertiary care hospital, Assam, India. Int J Reprod Contracept Obstet Gynecol 2018;7:1514-7. 